\title{
7 \\ Intergenerational transitions in rural Western Australia: an issue for sustainability?
}

\author{
Daniela Stehlik
}

\begin{abstract}
Towards the end of the past decade, signs were emerging as to future challenges associated with impending intersections between the ageing of global rural populations and their impacts on agricultural production and food safety. In a landmark paper for the Food and Agriculture Organisation (FAO), Iaquinta et al. (1999) made a strong plea for additional research in the field and developed a schematic highlighting the linkages between ageing, land tenure, intergenerational change and agricultural production for developing countries. The link to sustainability within this schematic was implied rather than highlighted and the importance of the issue for the developed world was glossed over. This chapter argues that this is a vital challenge for Australia now at the end of the first decade of the twenty-first century, as the country ages and the transition of knowledge from the 'baby boom' generation impacts at all levels of Australian society. It draws on continuing research being undertaken in Western Australia as part of an international research group focusing on sustainability and conservation. It takes up the schematic as designed by Iaquinta et al. and highlights the key issues for land tenure, the impact on rural values, natural resource management and future sustainability with specific focus on the south coast region of the state.
\end{abstract}

\section{Introduction}

Rapid transition from rural to peri-urban settlement in coastal southern Western Australia, combined with the potential changes in climate, demographic growth and intergenerational transitions, are creating potential future policy challenges. This has emerged as an issue for research within the context of the natural resource management (NRM) sector in the region and the concept of 'transitions' of knowledge and capital as Australia ages.

In a discussion about 'rural futures' for the developed world, a landmark paper written in 1999, which focuses on the issue for the developing world, offers 
some frameworks for discussion. This chapter draws on this framework to highlight key issues. It begins with a statement of the issue and some reflections from the literature; it then gives a snapshot of the region in question and of the evidence gathered to date, summarising some aspects of the framework and concluding with some questions for future research.

\section{Statement of the issue}

There has been recognition for more than a decade of the ageing of the farm workforce in Australia. As most reports point out, this is not simply because of an increased number of older farmers, but, importantly to our discussion, it is a result of decreased numbers of younger people entering or remaining in agriculture. The transition of farms and land management has a long history - for example, Foskey (n.d.:3) found evidence of intergenerational arrangements among landholders dating back to the Middle Ages. Barr et al. (2005), in their report to Land and Water Australia, point to the 'pattern of agricultural adjustment for many generations'. This chapter suggests that the issue has a more powerful difference as the whole Australian population ages.

There is also the important link with NRM policy in Australia. ${ }^{1}$ While risk assessments might highlight the NRM environment risks, they ignore risks associated with demography. For example, the major NRM regional strategy on the south coast of Western Australia (see below) identifies population decline and ageing as a threat on one page (p. 48) and it is never mentioned again.

This chapter is based not on empirical research (which has yet to be undertaken in detail in the region) but on personal involvement in NRM governance and on a close reading of policy documents for the region's future strategic planning. In other words, what I am highlighting here are preliminary signposts for the future, and I am calling for more detailed research. As a nation, we can no longer ignore the demographic trends, nor can we just hope that things will turn out for the best. While there has been a variety of risk assessments undertaken in rural Australia, at the time of writing, a risk assessment as to the impact of the ageing of the rural workforce ${ }^{2}$ on rural futures, or to the imminent intergenerational transfers of knowledge and power that are essential to enable a sustainable future, is not under way.

By transition here I am not so focused on the land transfer (this is where Voyce's 1999, 1996 work on inheritance sits), but rather on the experience, knowledge, social and cultural capital associated with the passing of one generation and the taking up of future challenges by other generations. Nowhere is this more evident that in the NRM 'sector'. Governance of NRM remains essentially in the hands of the older generation (very evident in my own region) and there is no evidence yet from a detailed literature review that any strategic thinking has taken this matter up as a key issue. There has, however, been much discussion about farm 
transfers, succession planning that focuses on the transition of the business, technology, stock, equipment and housing -in other words, an instrumental approach as follows:

Inheritance-legal transfer of ownership of the business assets

Succession - transfer for managerial control over the use of these assets

Retirement - the withdrawal of the present manager from active managerial control. (<http://www.management.edu.ru/images/pubs/ 2003/11/29/0000135240/075-067-errington.pdf >)

Such a typology captures the essence of the literature to date, specifically the practical and productive nature of any transition. My current research is highlighting a little-explored aspect of the intergenerational shift - the transition of knowledge in governance-an aspect that is crucial for our deeper understanding of rural futures, and the potential impact of the ageing of Australia's population on NRM and food safety into the future.

Four years ago, in its submission to the Department of Agriculture, Fisheries and Forestry (DAFF) on 'Agriculture Advancing Australia' (AAA), the National Farmers Federation (NFF) stated that as the average age of farmers was now close to sixty years, to ensure the long-term prosperity and sustainability of Australian agriculture, effective intergenerational transfer was essential. The report, Australia's Farmers: Past, present and future (Barr et al. 2005), examines trends in the demographic structure of Australia's farmer population throughout the period 1976 to 2001 and concludes that there is no looming crisis with Australia's food production capacity, despite the expected continued decline of farmers in broadacre farming regions. The report conceptualises intergenerational transfer as related to farm size and this is explored from the perspective of farm development, innovation and how technology can impact on levels of production. The report argues that protection of the rural environment through farming practices is anticipated to be continued as long as the activities are labour efficient and profitable or if they are required by regulation.

Argent (1999) suggests that the established gender order within Australian farming households is undergoing gradual and uneven change as a familial ideology - in which the maintenance of family living standards is considered more important than the preservation of the family's ties with the land-assumes importance in some young families' adjustment responses. Voyce (1999) explores issues of farming succession with particular reference to the Social Security and Veterans' Affairs Legislation Amendment (Retirement Assistance for Farmers) Act 1998. He outlines that this legislation seeks to: 1) maintain political and social control in the rural sector; and 2) foster intergenerational continuity of family farms. He argues that the State's involvement is in 'facilitated and ordered controlled successions' tending to be through the establishment of rural norms 
or 'responsibilities' between an inheriting son and father (Voyce 1999:22). Foskey (n.d.) discusses two main but opposing trends within agriculture in Australia - farming as a lifestyle and farming as a business - both of which are linked to rural ideology. ${ }^{3}$ The ageing of farm populations is a worldwide trend, with the highest rates in the United States, Canada, Europe and Japan. Foskey concludes by highlighting the need to support ageing farmers as they make the transition into retirement and the challenges they face in this, as well as utilising their skills and experience to further enable younger farmers. Errington's 2002 review of the topic in the United Kingdom, France and Canada concludes that there is a sequencing of transition, including major decision making along the process, although in France this seems to be more rapid than in the United Kingdom (<http://www.management.edu.ru/images/pubs/2003/11/29/ 0000135240/075-067-errington.pdf $>$ ).

\section{A region in context}

The chapter now turns to the site of analysis. The south coast region of Western Australia ${ }^{4}$ has some of the world's most endangered flora and fauna, is recognised as one of 25 world biodiversity 'hot spots', covers a land mass of some 5.4 million hectares in what is arguably a high-amenity area and is now experiencing rapid change. This is one of the oldest areas of human settlement in Australia, with Aboriginal settlement dated to 40000 years and European settlement (around the Albany area) to the 1820s. Unlike the Margaret River (south-west) region of Western Australia, it is not yet as well known internationally, although this is changing.

It is the state's second-largest agricultural production region. Despite the historical records showing a 30 per cent decrease in average rainfall for south-west Western Australia, the region had relatively positive rainfall in the 2006-07 season. About 70 per cent of the region's 5.4 million terrestrial hectares is under some form of primary production, the majority being cropped (including wheat, canola, and so on) or under pasture, but with more than 125000 ha under timber plantations and about 4000ha under viticulture and various forms of horticulture (SCRIPT 2005:76). This intensive agriculture has resulted in four identified major environmental challenges for agricultural production:

- $\quad$ soil acidity

- $\quad$ salinity

- excess phosphorous (excess fertiliser usage)

- invasion of weeds and feral animals. 
To provide a brief snapshot of the costs associated with such threats, land salinisation offers a salutary lesson. By the late 1990s, 9 per cent of Western Australia's agricultural land was affected by salinity and predictions identified a doubling in the next 15-25 years, with a further doubling in the next decades. The WA State of the Environment Report (Government of Western Australia 1998:56) detailed that 'up to 80 per cent of susceptible remnants of native vegetation of forms and 50 per cent on public lands (including nature reserves) could be lost in the agricultural regions of W.A. within the next century'. It has been estimated that the current loss of capital value of WA land to dryland salinity is in the order of $\$ 1.445$ billion, with a prediction to an escalation of a further $\$ 64$ million per annum in the next five decades. It is not, however, just the land value that is decreasing; estimates of tourism potential are also impacted, as are the livability and amenity capacities of small rural centres and the potential production of agricultural products.

The south coast region of Western Australia is one of 58 NRM regions in Australia and it is being managed through the South Coast NRM Incorporated. It is also the site of a five-year research project by Curtin University, Sustaining Gondwana, funded through a grant from the Alcoa Foundation (United States). The site was chosen for this research because the region provided an example of the complex interrelationships between place, environment, production and sustainability.

In the 18 months since the start of our project, the pace of change has increased exponentially. For example, in the major western centre of the region, Albany, there has been a 37 per cent increase in the price of housing, with a projected release of more than 2000 new blocks in the next five years. The pressure of demographic change (see Stehlik 2007; Government of Western Australia n.d.) is now recognised as a key issue for future sustainability.

This chapter examines questions of change through what is termed the Albany hinterland, a broad arc surrounding the City of Albany and including the Shire of Denmark. Many of my comments apply to the region as a whole. The Albany hinterland subregion takes in the city of Albany and the towns of Denmark, Mount Barker, Manypeaks and Wellstead. It contains all of the Denmark, Hay and Kalgan River catchments flowing south from the Stirling Range and discharging into Wilson Inlet and Oyster Harbour. 
Figure 7.1 South coast of Western Australia

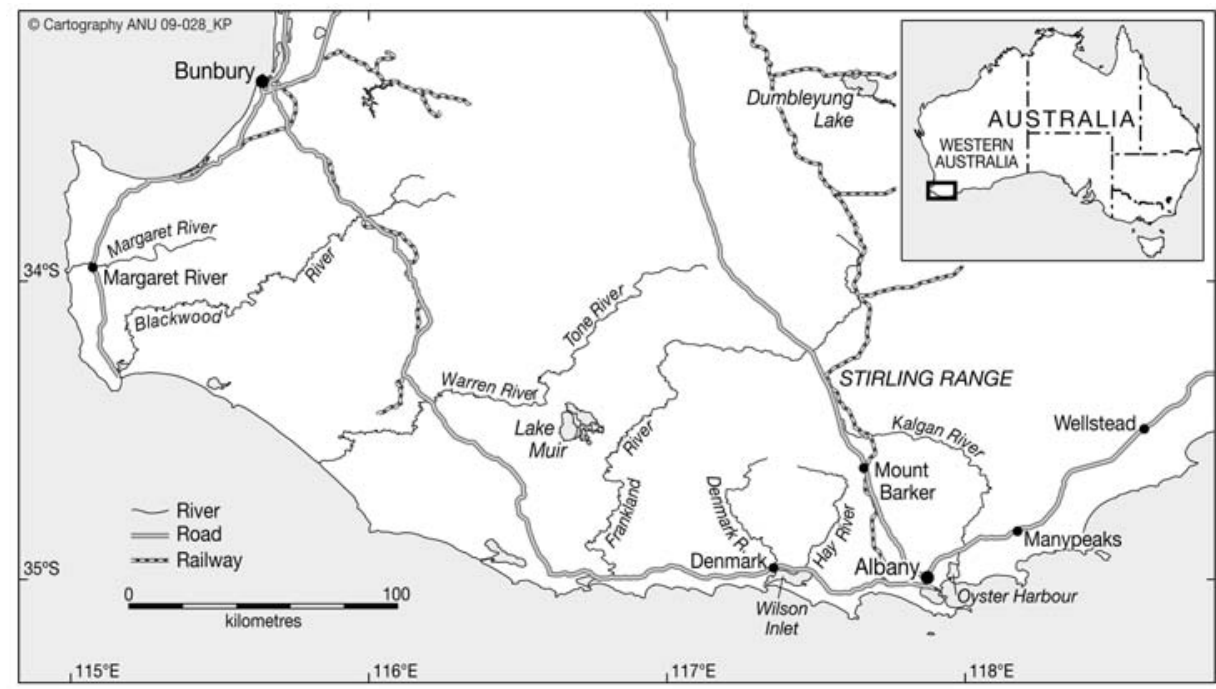

Source: ANU Cartography.

ABS Census data highlight the trend towards the urbanisation of the south coast region, with nearly three-quarters of the population living in the two key urban centres of Albany and Esperance. Consequently, the population in the smaller rural villages - such as Tambellup, Gnowangerup, Jerramungup and Cranbrook - are decreasing (Figure 7.2).

The proportion of the population in the Albany Hinterland of the region as a whole is 62.6 per cent and growing. In this sense, the urban centre of Albany can be seen as acting as a 'sponge city' — pulling services and residents into the urban space, at the cost of the rural outlying communities. There was a reduction of some 7-10 per cent in the populations of the smaller rural centres in the south coast region in the 2001 census and this pattern was expected to be repeated despite some early indications of a 'tree change' housing boom in some centres such as Mount Barker. 
Figure 7.2 Population change, 1996-2006, Albany and Denmark

\section{Population Change - Albany/Denmark LGAS}

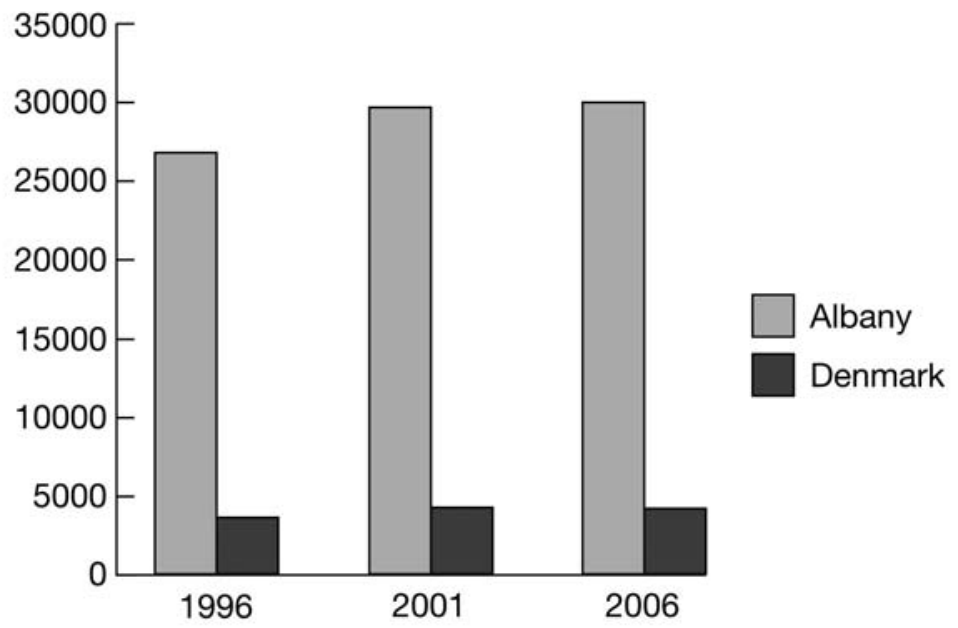

Source: Derived from ABS (2007)

Figure 7.3 Population aged 55-64 years, 1996-2006, by shire (Jerramungup, Gnowangerup, Tambellup and Cranbrook - Albany hinterland)

55-64 years x Shire 1996-2006

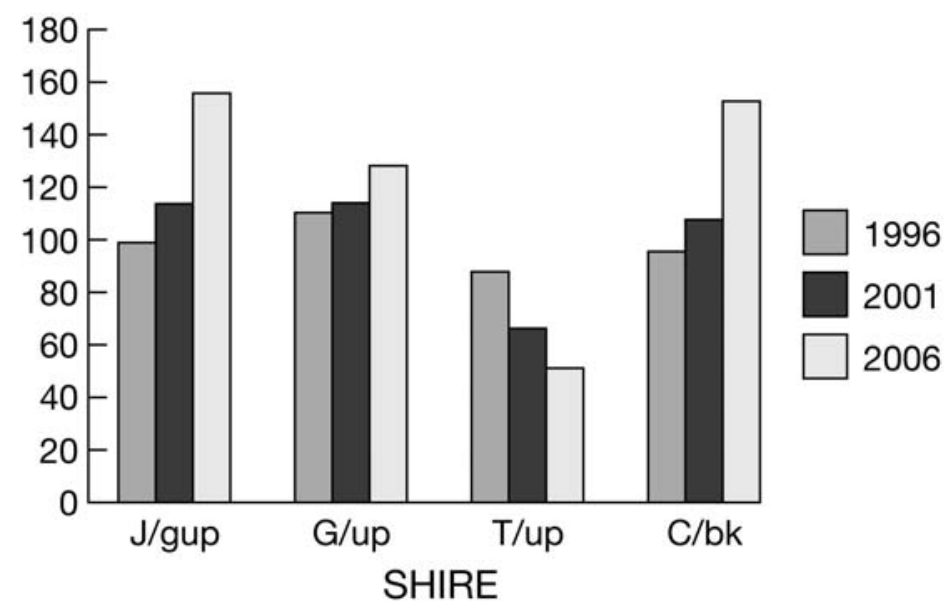


Figure 7.4 Population aged over 65 years, 1996-2006, by shire (Jerramungup, Gnowangerup, Tambellup and Cranbrook - Albany hinterland)

\section{Over 65 years x Shire 1996-2006}

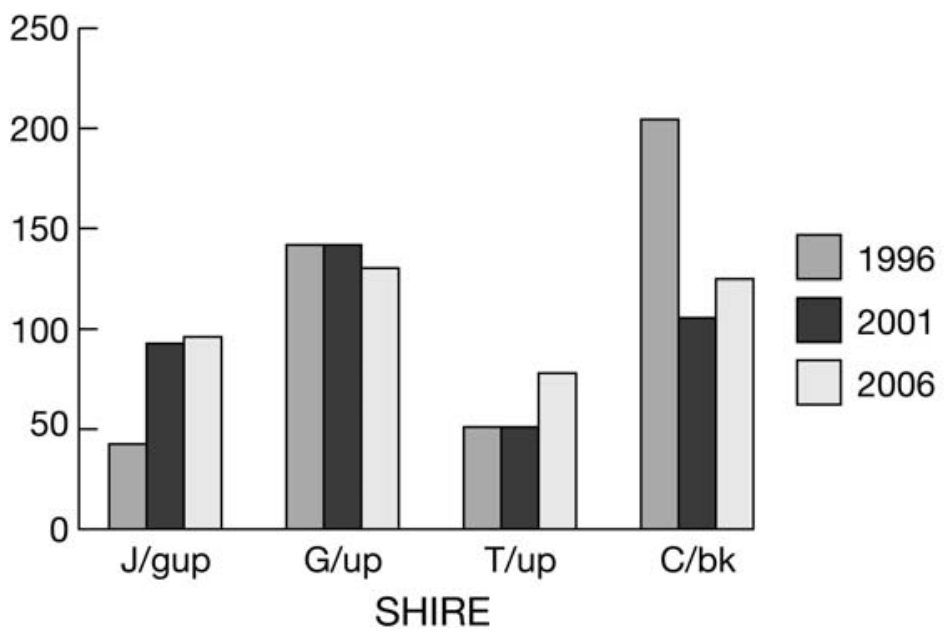

There have been many predictions by the City of Albany that the population will continue to increase at 3 per cent per annum in the foreseeable future, and this in turn is placing increasing pressure on the demand for the release of land. The latest data from the 2006 census have, however, challenged such predictions. Nevertheless, the perception of demographic pressure has in fact changed the land usage in the immediate periphery of Albany: peri-urban land is becoming more urban and less rural.

The other important aspect of our brief demographic analysis is the proportion of those in the population aged more than fifty-five years (see above). In a state that is experiencing an unprecedented resources boom, we are also seeing the direct impact on skills shortages and, in the case of agriculture, even less interest in the sector as a long-term career opportunity. Young people are being led away from the sector and into another sector, which appears to offer more future opportunities as well as more immediate income. The latest ABS data put the proportion of the population aged more than fifty-five in the City of Albany at 27.8 per cent and in the Shire of Denmark at 33.4 per cent - which is high compared with the 24 per cent overall for Australia. In their analysis of the whole Australian population, Barr et al. (2005:1) suggest that 'since the 1991 census the rate of exit of older farmers (aged over 60) has been slowly declining. Retirement is being delayed, ${ }^{5}$ possibly in response to the fewer numbers of young persons seeking to take over family farms.' 
In the same report, Barr et al. also highlighted that the rate of exit of older farmers (aged over sixty) fell during the 1990s. They make the point that farmers 'are retiring later. This appears to be counterbalancing the continued higher rates of exits of younger farmers, causing the median age of exit to again rise towards 58 years of age' (Barr et al. 2005:17).

\section{Land use}

The south coast region of Western Australia has traditionally been viewed as a 'rural' area. In Australian terms, this means that the majority of economic production has been agricultural. As I will explain shortly, this balance is shifting rapidly. Among other important trends in the past decade, in

the north-eastern part of the subregion, there is a trend towards fewer, larger broad acre farms focusing on traditional and diversified cropping and livestock industries. In the south-western part of the subregion, landholdings are becoming smaller with more focus on intensive and diverse agricultural systems. New industries that have been established or are evolving in the subregion include viticulture, timber production, farm forestry, olives and fishing. The subregion is also renowned for its tourism, recreational and nature conservation values. (SCRIPT 2005:14)

Table 7.1 provides an explanation of current land use.

\section{Table 7.1 Albany hinterland land use}

\section{Albany Hinterland - Land Use (2004)}

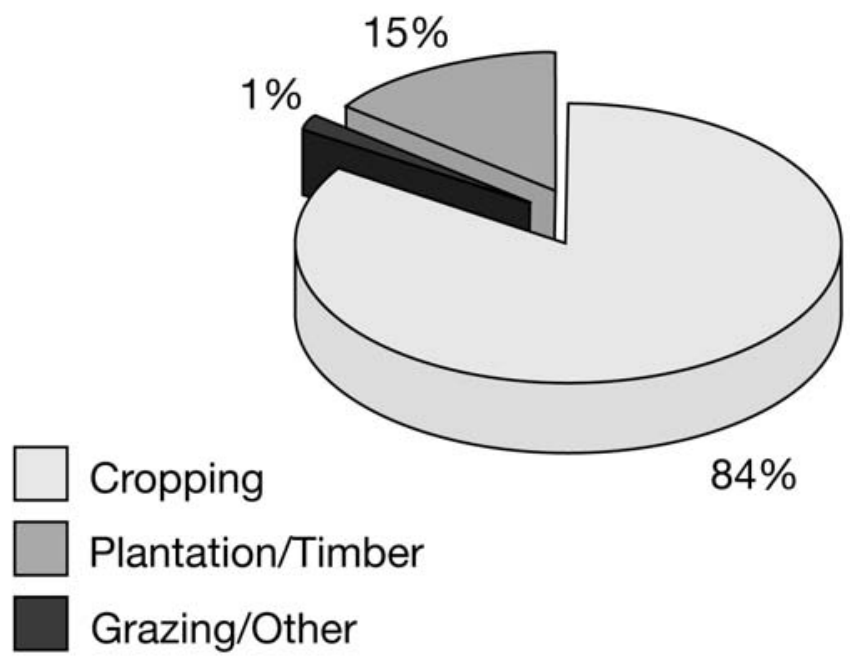

Source: Derived from SCRIPT (2005:78). 
The establishment of tree crops in the past decade, particularly in the higher rainfall areas, has marked a significant change in the region's land uses. By far the largest areas have been planted to blue gums. A woodchip plant at Mirambeena, north of Albany, and export facilities at the Port of Albany are now significant contributors to the region's economy (SCRIPT 2005:76).

Some 354867 ha of a total of 617155 ha (57.5 per cent) are in production. It should be noted that in real terms the value of agricultural land has remained stable.

There has, however, been a shift, not only in production, but in off-farm activity. In line with the rest of Australia, farmers in the south coast region need to supplement their income, as highlighted in Figure 7.6.

Figure 7.6 Farm income/off-farm income, south coast region

\begin{tabular}{|l|r|r|}
\hline Local Government & Albany & Denmark \\
\hline Cropping & 263,311 & 35,841 \\
Dairy & & 321 \\
Grazing & & 3,756 \\
Hardwood & 401 & 250 \\
Plantation forestry & 49,008 & 1,299 \\
Seasonal horticulture & & 22 \\
Softwood & 656 & 2 \\
\hline
\end{tabular}

Source: Stehlik (2007).

\section{A framework for analysis}

Having laid out the context, I now turn to an explanation of the framework as proposed by Iaquinta et al. (1999) in their paper for the Sustainable Development Department and the FAO of the United Nations. The purpose of this paper was to establish the effects of demographic ageing on intergenerational transfers of land. It also focuses largely on the developing world, where land tenure is often fragile and not systematised. This framework could assist us in our discussions here and I am therefore going to explain the framework, then use it to discuss the south coast Albany hinterland. Iaquinta et al. (1999) identify six aspects of land and land-associated transfers: 
- institutionalisation mechanisms

- property involved

- people involved

- duration of arrangement

- nature of entitlement

- specification of use.

Importantly for our discussion, however, they also identify other types of intergenerational transfers: other 'goods', not just property, which can be transferred between generations. These are important in our intersecting discussion of rural futures, NRM and sustainability. The other types of transfers are:

- ownership and control of non-land resources (such as money, financial investments, water rights, stock, and so on)

- control of information and membership of information networks (social, trade, political, and so on)

- formal and quasi-formal positions in a community.

In regard to the last category, the framework highlights the 'relevant privileges and rights, as far as control over the transfer [of this capital] rests with the current occupant and is not subject to a formal authorisation mechanism [such as elections, and so on]' (Iaquinta et al. 1999:4). I will return to these issues again in the discussion. The authors then discuss the mechanisms through which intergenerational transfers can be affected by the ageing of the population. They have identified 10 categories, and then asked some questions to enable analysis as follows:

- change the timing of the transfer

- change the duration of the transfer

- change the mix of assets transferred

- change the completeness of the transfer

- change the generations involved in the transfer

- change in who makes the decision to transfer

- change the usual recipient of the transfer

- change the value of the goods to be transferred

- change the relevance of the transfer to the intended recipient

- changes in settings where communal lands dominate.

\section{Intergenerational transitions}

I want to highlight a couple of these points for more detailed discussion within the context of the south coast region: changing the timing of the transfer and changing the mix of assets transferred. 


\section{Change the timing of the transfer}

Both points are relevant to my argument that it is more than the land itself that is transferred. Iaquinta et al. (1999) point out that as life expectancy increases, the transition time changes. In addition, in developed countries, the 'empty nest' and the fluctuations of agricultural production also mean that, in many cases, the next generation has already left the farm well before there is any serious contemplation of transfer. It is often difficult to entice the younger generation to return to the property and, in many cases, current farmers are often reluctant to pass on the stress and uncertainty. Research in Queensland and New South Wales in the mid 1990s highlighted the dilemma that many farmers felt about their role as 'stewards' for their children on the one hand, and the demands and stresses they were themselves experiencing on the other, which they felt reluctant to 'pass on' as an inheritance (Stehlik et al. 1999).

We are already well aware that rural land management tends not to be able to afford employed labour. In the WA south coast region, evidence suggests that any instrumental 'transfer' of property is therefore more likely to be a sale - often to a neighbour ${ }^{6}$ - who of course is usually also within the age range that we are considering. This is linked to a trend towards larger properties in the north-western part of the Albany hinterland. The other aspect of timing is that changes in agricultural production - evident in the south coast particularly in relation to plantation timber, grape production for wine and smaller properties with more 'boutique'-style horticulture - appear to be more attractive than traditional broadacre systems, and can, of course, be carried out closer to the regional centres (thus enabling a combining of lifestyle with off-farm income potential). Across the Great Southern region itself, the median size of properties has reduced by about 16 per cent in the past five years. The pressure is on those who are currently on the property to remain there.

Iaquinta et al. (1999) ask: '[H]ow does population ageing influence the ages of donors and recipients? Do the family life stages of persons involve change with population ageing? Is the recipients' life cycle situation important in relation to agricultural production?'

\section{Change the mix of assets to be transferred}

This aspect is of importance if we are considering 'rural futures'. The transfer by the older generation of social and cultural capital - other than financial capital (that is, the farm) - is very important in relation to any sustainability of the rural sector. As we are all now well aware, social and cultural capital are essential to the integration of networks, trust relationships, mutuality and the essential health of any community. This has become an overt issue for those who are focusing on research of increased production: 
[A] major challenge in the agricultural industry is maintaining a positive social fabric. Tensions between the achievement of financial and social goals will prompt some farmers to leave the industry while others will adapt in an attempt to achieve both ends, for example fly-in/fly-out farm management. (Professor D. Pannell, cited in the Great Southern Farmer, 28 March - 3 April 2007:7)

One of the positive advantages of the Albany hinterland is that it is relatively accessible to Albany and Denmark and the 'drive-in/drive-out' opportunities could well encourage more intergenerational transitions. Nevertheless, at present, the transition is a fragile one, with there being no strategic planning either within agriculture or within the NRM sectors, while the governance of both sectors remains essentially in the hands of the older generation, and the younger generation does not demand its place at the table. Iaquinta et al. (1999:5) ask (in relation to the developing world), '[W]hat could the elderly gain from such protracted transfers?...[Perhaps] to create intergenerational exchanges while keeping back enough to assure that the process will continue and that the quality of life in their own ageing period will not suffer.'

Is there a similar trend in the Albany hinterland? We do not know and will not know unless detailed empirical research is undertaken. We need to ensure that any discussions about rural futures and NRM start taking a good hard look at who is involved and how the transition of knowledge and power between the generations is being promoted and encouraged. This is not only at the level of government policy, but practically at the level of service delivery, extension and research.

Iaquinta et al. (1999) ask: 'Does population ageing influence the composition of assets that are being transferred between generations? Do the exchange relationships change? Does population ageing affect the gender aspect? What is the impact of these on agricultural production?'

\section{Some preliminary reflections}

How does this present us with possible rural futures?

1. The increasing demand within NRM for 'social sustainability/social indicators' - indeed, social anything - is in large part due to the fact that we have tended to ignore the obvious and focus on what appears more 'simple', namely, the environment. As I mentioned earlier, while there have been any number of risk assessments, and by latest count the south coast NRM has funded many millions of dollars into this activity, they are all limited in scope. The human dimensions associated with NRM and rural Australia, while on the agenda, have yet to receive the comparative funding essential to undertake the empirical detailed work that Iaquinta et al. (1999) called for. 
2. It remains unclear where the responsibility for this should lie. Demographic change - like climate change - is difficult to 'box in' or 'silo' into one department or one agency. While the WA Department of Agriculture and Food has always taken primary agency responsibility for farmers, it has tended not to focus on their ageing, but rather on their capacity for production. Its main activity therefore remains extension. Once farmers 'retire' they are no longer included. Linkages at the local level between health, community services, local government, and so on regarding intergenerational transitions are very much in the early stages-and everyone is looking for leadership. Where should it come from? The related issue is how can we continue to capture the expertise, experience and knowledge from the older generation?

3. The transitions from broadacre to boutique farming evident in the Albany hinterland are being promoted through activities such as the 'slow food' movement and farmers' markets, as well as through tourism and the hospitality industry. Could this be indicative of a developing differentiation of 'trendy' agriculture and 'non-trendy' agriculture? If so, what does this mean for food safety?

4. The increasing incorporation of off-farm income into farm families' budgeting does not appear to be slowing. Despite the Albany hinterland doing somewhat better than the rest of Western Australia in terms of rainfall, in the period we saw that off-farm income has increased. The proximity of farms to regional centres becomes doubly important-not just for such employment opportunities, but to enable the work/life balance so essential for future social cohesion and social capital. It appears that the increasing sponge-like impact of larger centres will continue.

5. Will the baby boomers ever give up power? What kind of intergenerational transitions will Australia experience in the next 25 years? How will these be played out? What is the importance of 'place' in such transitions? We simply do not know yet.

6. Finally, what impact will these intergenerational shifts have on the assumptions we have made about the governance of NRM in the future? So much of south coast NRM governance is in the hands of the older generation now. We need to be thinking about what transitions will take place.

\section{Conclusions}

Iaquinta et al. (1999), while focusing on the developing world, offer some questions pertinent to our contemplation of rural futures in Australia. From the time of presenting this paper to the seminar to its publication, a new Federal Government has taken office and rural Australia waits anxiously to see what impact the new Labor Government will have on rural policy, NRM governance 
and the general ageing of the population. In the meantime, the drought along the eastern seaboard has eased after widespread flooding, while drought continues to be declared in the northern half of the West Australian wheatbelt. Western Australia's rural futures are still dependent on the current and continuing resources boom as the skills shortage in the agricultural sector becomes more acute. Australia's rural futures remain unpredictable and vulnerable to the vagaries not only of climate variability, but to rural policies and demographic change.

\section{Bibliography}

Argent, N. 1999, 'Inside the black box: dimensions of gender, generation and scale in the Australian rural restructuring process', Journal of Rural Studies, vol. 15, no. 1, pp. 1-15.

Arkle, P. 2003, Submission to the Department of Agriculture, Fisheries and Forestry-Australia (AFFA), Agriculture Advancing Australia (AAA) Review, Policy Manager-Rural Affairs, National Farmers Federation, viewed 10 July 2007, <http://www.nff.org.au/pages/sub/AAA\%20Review\%20Submission.pdf>

Australian Bureau of Statistics (ABS) 2007, 2006 Census Quick Stats. Denmark. Albany, Australian Bureau of Statistics.

Barr, N., Karunaratne, K. and Wilkinson, R. 2005, Australia's Farmers: Past, present and future, Land and Water Australia, Canberra, viewed May 2007, <http://products.lwa.gov.au/files/PR050941.pdf>

Foskey, R. n.d., Australian Agriculture, Ageing and Adaptation: At the forefront of a world-wide phenomenon?, Institute for Rural Futures, University of New England, Armidale, New South Wales, viewed 10 July 2007, $<$ http://netenergy.dpie.gov.au/corporate_docs/publications/word/industry_dev/ aaa/australian_ag_ageing_adaptation.doc $>$

Government of Western Australia n.d., Indicators of Regional Development in WA, Government of Western Australia, Perth.

Government of Western Australia 1998, Environment Western Australia 1998. State of the Environment Report, Department of Environmental Protection, Perth.

Government of Western Australia 2002, Population characteristics and trends. Update. Western Australia's seniors, Topic Sheet No. 1, edn 2, Government of Western Australia, Perth.

Government of Western Australia 2004, A Profile of Western Australia's Seniors, Government of Western Australia, Perth. 
Iaquinta, D., du Guemy, J. and Stloukal, L. 1999, Linkages Between Rural Population Ageing, Intergenerational Transfers of Land and Agricultural Production: Are they important? SD dimensions, Sustainable Development Department, Food and Agriculture Organisation of the United Nations, viewed 18 January 2007, <http://www.fao.org/sd/wpdirect/wpan0039.htm>

SCRIPT 2005, South Coast Strategy for Natural Resource Management-2004-2009, SCRIPT, Albany.

Stehlik, D. 2007, Whose sea-change? Some reflections on transformations in the City of Albany, Sustaining Gondwana Working Paper Series, Issue 2, April, Curtin University of Technology, Perth.

Stehlik, D., Lawrence, G. and Gray, I. 1999, Drought in the 1990s. Australian farm families' experiences, Rural Industries Research and Development Corporation No. 99/14, Canberra.

Voyce, M. 1996, 'Ideas of rural property in Australia', in G. Lawrence, K. Lyons and S. Momtaz (eds), Social Change in Rural Australia, Central Queensland University, Rockhampton, pp. 95-105.

Voyce, M. 1999, 'How ya gunna keep 'em down on the farm? Giving it all away: the role of the State in the intergenerational exchange of the farm', Alternative Law Journal, vol. 24, no. 1, pp. 22-9.

\section{Endnotes}

${ }^{1}$ NRM implies the legislative and institutional governance of natural resource management activities in Australia.

2 In the context of the discussion at the symposium, the 'workforce' is predicated on a definition of work as paid and unpaid.

${ }^{3}$ Further discussion of Australian rural ideologies can be found in companion chapters.

4 All details are drawn from SCRIPT (2005).

${ }^{5}$ Confirmed by a recent University of Tasmania study reported in The Australian (12 July 2007).

6 There is also some evidence that farms are being bought for investment and managed by external companies. 